\title{
Mathematical Models in Predicting Retention of STEM Students in Pre-Calculus
}

\author{
Norman Cuello Barroso ${ }^{1 *}$ (])
}

${ }^{1}$ Tanza National Comprehensive High School, PHILIPPINES

*Corresponding Author: normancuellobarroso@gmail.com

Citation: Barroso, N. C. (2020). Mathematical Models in Predicting Retention of STEM Students in Pre-Calculus. International Journal of Pedagogical Development and Lifelong Learning, 1(1), e02004. https://doi.org/10.30935/ijpdll/8342

\begin{abstract}
This study aimed to determine the mathematical models in predicting retention of STEM students in Pre-Calculus. The study utilized a non-experimental research specifically a cross-sectional predictive design. The independent variables in the study are the Grade Point Average (GPA) in Mathematics 10, General Weighted Average (GWA) in grade 10, National Career Assessment Examination (NCAE) - mathematical ability, NCAE - STEM results, gender and family monthly income. The dependent variable is the retention of STEM students in Pre-Calculus. The instruments in the study are Pre-Calculus Retention Test (PRT), interview and documentary analysis. The PRT was validated by five experts and underwent reliability testing with a Cronbach alpha value of 0.524 . Percentage, mean, standard deviation, Pearson Product Moment Coefficient of Correlation and Multiple Regression Analysis were applied in the study. The researcher used IBM SPSS version 20 in analyzing the data gathered. The study developed two mathematical models that can predict retention of STEM students in Pre-Calculus. Using the standardized coefficients, the formula in predicting retention of STEM students in Pre-Calculus are $\mathrm{y}=0.035 \mathrm{x}_{1}+0.632 \mathrm{x}_{2}-31.462$ and $y=0.033 x_{1}+0.599 x_{3}-28.370$ where $y$ is PRT scores of the STEM students, $x_{1}$ is NCAE-Mathematical Ability scores, $\mathrm{x}_{2}$ is GPA in Mathematics 10 and $\mathrm{x}_{3}$ is GWA in grade 10. . It can be gleaned on the mathematical models that the best predictor of the retention of STEM students in Pre-Calculus are GPA in Mathematics 10 and GWA in grade 10.
\end{abstract}

Keywords: pre-calculus retention test, mathematical models, multiple regression analysis, NCAE

Received: 22 May 2020 - Accepted: 2 Jun. 2020

\section{INTRODUCTION}

Mathematics Framework for Philippine Basic Education (2011) states that the goal of mathematics education at the basic education level is to "provide opportunities for individuals to develop skills and attitudes needed for effective participation in everyday living and prepare them for further education and the world of work so that they make worthwhile contributions to the society at large". Mathematics in Philippine education is seen as a contributing factor to the participation in productive life activities, as means to make sense of the world, as medium for communication and a gateway to national progress. However, statistics from different international assessment reflect Filipino students' low performance in Mathematics. The Trends in International Mathematics and Science Study (TIMSS) in 2003 ranked Philippines $34^{\text {th }}$ out of 38 countries. Furthermore, data from the Global Competitiveness Report in 2011-2012 show that Philippines ranked 115th out of 142 countries while 67th out of 140 in 2015-2016. In the latest 2016-2017 data, Philippines ranked 79th out of 138 countries. Makabenta in his Manila Times article dated January 21, 2017, pointed out that the Philippines chickened out of the 2015 Program for International Student's Assessment (PISA) in an argument that the education officials during that time ran away from the assessment because of the fear that young Filipinos were not prepared for such test. PISA evaluates education system in 70 countries by testing the academic ability of 15-year old students in each country. This is not a call but a thrust for Filipino mathematics educators to strengthen and increase the retention of students in Mathematics so that Filipino students can elevate their ranks in PISA and TIMSS.

Currently, Philippine educational system is following a K to 12 curriculum which was implemented by the former Department of Education secretary, Bro. Armin F. Luistro under the Republic Act No. 10533. As cited by Chan (2019), this is an act to enhance the Philippines basic education system by strengthening its curriculum and increasing the number of years for basic education, appropriating funds therefore and for other purposes. One of the main reasons why the former secretary implemented this is because the Philippines is one of the few countries that is still offering a 10 - year basic education curriculum. In order to jive with the international educational trend therefore there is a need to apply kindergarten +12 -year basic education curriculum. The additional 2 years shall comprise a senior high school program as set by the law. The senior high school offered academic track, technical vocational track, sports track and arts and design track. 
Furthermore, Pre-Calculus is one of the specializations taken by the students who will enroll in academic track under Science Technology Engineering and Mathematics (STEM) strand. The topics covered by this subject are analytic geometry (conic sections), number theory (mathematical induction) and trigonometry (circular functions, graphs of trigonometric functions, trigonometric identities and polar coordinates). Most of the schools offered this subject during the 1st semester of the grade 11 STEM students because this is a prerequisite subject before they can enroll in other specializations like Basic Calculus and General Physics I. It only implies that students should master the concepts and topics being discussed in Pre-Calculus since this has connections with the other specializations. In addition, based on DepEd Order No. 55 s. 2016, the qualifications before the students can enroll in STEM are the GPA in Mathematics 10 and Science 10 should be at least 85 and the score in NCAE under STEM category should be at least 80. Some of the schools also utilize the entrance examination in choosing students who can enroll in STEM. With the extensive qualifications in STEM, it only means that students in this strand are intelligent specifically in Science and Mathematics. However, according to the Guidance Counselor at Tanza National Comprehensive High School - Senior High that in academic year 2017 - 2018, there are 2\% of the STEM students decided to transferred to the other schools and $5 \%$ of the STEM students decided to shift to the other strands like Accountancy and Business Management (ABM) and Humanities and Social Sciences (HUMSS). Based on the interview of the guidance counselor to the students, one of the reasons why they chose to transfer or shift to other strands is because of their difficulty in coping with the specializations like Pre-Calculus and General Chemistry I. Since there are qualifications, therefore teachers are expecting that students are mathematically inclined wherein they can easily cope up with the lessons in Pre-Calculus. Teaching mathematics always incline to a narrow set of procedures that students are expected to reproduce at high speed timed tests, speed pressure and the 'usual' procedural teaching. Thus, teaching strategies and techniques have something to do with this kind of predicament. However, based on the result that there is a huge difference in the pre-test and post-test scores of the respondents of the study (STEM students) in Pre- Calculus. The mean percentile score of pre-test is $24.83 \%$ and it increased in the mean percentile score of post-test which is $79.85 \%$. It means that the strategies and interventions of the teacher like group study, cooperative learning, reward system and the use of technology like desmos application are effective.

According to the Pre-Calculus teacher, all STEM students have high grades in Mathematics 10, but the students are not ready since most of them have weak foundations in Algebra. This was uttered by the teacher because when he discussed the lessons in Pre-Calculus, he needs to recap and review some of the basic mathematical concepts related to the competencies. Impliedly, students may learn the topics in Mathematics, but they have short term memory wherein they can easily forget the skills and knowledge they learned from their Mathematics teacher. This is the reason why retention of students in Mathematics is one of the main problems of the teachers. There are lot of research that suggest effective interventions for retention like educomp classroom (Sharma, 2016), reform-based instructional method (Modebelu et al., 2014), Polya George's Problem solving Model (Nneji, 2013), differentiated instructional strategies (Ogunkunle \& Henrietta, 2014), cooperative learning (Ahmed Gubbad, 2010), ethnomathematics
(Kurumeh, Onah, \& Mohammed, 2012) and concrete manipulative approach (Akaazua, Bolaji, Kajaru, Musa, \& Bala, 2017).

Nowadays, understanding of mathematics is critical in the age of STEM (Furner, 2017). This calls for a proper intervention that will involve STEM students with different learning activities and engage their parents in the learning process (Staus et. al, 2020). On the other hand, Hassan (2020) cited that the utilization of technology and engineering in real, realistic and meaningful ways could probably escalate the learning of STEM students in Mathematics. Also, Siregar et. al (2020) pointed out that the implementations of STEM programs are educationally significant for students' achievement in mathematics. The different learning interventions from previous research about STEM education could probably a tool on elevating retention of STEM students in Mathematics.

Moreover, Kurumeh (2012) said that retention is measured in collaboration with achievement. This means that retention is closely related to achievement. This is the reason why this study opted to include GPA in Mathematics 10, GWA in Grade 10, NCAE (STEM) and NCAE (mathematical ability) as valid predictors on the retention of STEM students in Pre-Calculus. Also, Scholastic Aptitude Test Mathematics score and high school performance are strong predictors of the students' retention (Alkhasawneh \& Hargraves, 2014; Mbuva, 2011; Radunzel \& Noble, 2013).

Predicting students' retention in Mathematics specifically in PreCalculus is therefore an increasing concern of most of the senior high school who are offering STEM strand. This is the reason why this study will develop mathematical models in predicting retention of students in Pre-Calculus. The models will be developed through the utilization of multiple regression analysis. With the help of the different mathematical models, the teachers and administrators can predict the success of students in taking STEM. Although the developed mathematical models are not exactly accurate, but it would really help the stakeholders of the senior high school in accepting STEM students.

\section{STATEMENT OF THE PROBLEM}

This study aimed to develop mathematical models that can predict retention of STEM students in Pre-Calculus.

This study sought to answer the following questions:

1. What is profile of the STEM students in terms of the following: - Gender;

- Family Monthly Income;

- National Career Assessment Examination (NCAE) mathematical ability; and

- National Career Assessment Examination (NCAE) STEM?

2. What is the academic performance of the STEM students in terms of the following:

- General Weighted Average (GWA) in Grade 10; and

Grade Point Average (GPA) in Mathematics 10?

3. What is the mean retention score of the STEM students in PreCalculus?

4. Is there a significant relationship between the retention of the STEM students in Pre-Calculus and the following independent variables:

- Gender; 
- Family Monthly Income;

- National Career Assessment Examination (NCAE) mathematical ability;

- National Career Assessment Examination (NCAE) STEM;

- General Weighted Average (GWA) in Grade 10; and Grade Point Average (GPA) in Mathematics 10?

5. What mathematical models can be used in predicting the retention of students in Pre-Calculus?

\section{METHODOLOGY}

This study utilized a non-experimental research specifically a crosssectional predictive design. The independent variables in the study are the GPA in Mathematics 10, GWA in grade 10, NCAE- mathematical ability, NCAE - STEM results, gender and family monthly income. The dependent variable is the retention of STEM students in Pre-Calculus. The researcher used independent variables that can predict the retention of STEM students in Pre-Calculus.

The respondents of the study are the grade 11 - Science and Technology Engineering and Mathematics (STEM) students of Tanza National Comprehensive High School (TNCHS) - Senior High, North District of the Division Cavite during the first semester of the school year 2018 - 2019. The study used total enumeration wherein all the grade 11- STEM students were the participants of the study. There are two sections of STEM strand at TNCHS - Senior High. These are composed of 53 students of STEM 11Q and 50 students of STEM 11R. The total number of participants is 103 .

\section{Data Gathering Procedure}

Letter of Intent: The researcher secured permission to the office of the school principal to inform about the proposed study. The letter includes the objective and significance of the study.

Validation Phase: The researcher asked three mathematics experts, one psychometrician and one senior high school teacher who has doctorate degree to validate the Pre-Calculus Retention Test that was made by the researcher. Letters were sent to the experts for the permission to act as validators of the instrument.

Instrument Testing: The Pre-Calculus Retention Test underwent reliability testing. The validated PRT was tested to the grade 12 STEM students to measure the reliability of the examinations. The Cronbach alpha value of 0.524 was revealed which implies that there is an internal consistency of each item on PRT.

Survey Questionnaire to the Participant: The participants were given survey questionnaire by the researcher to determine the gender and their family monthly income.

Academic Data Gathering: The researcher secured the permission of the guidance counselor in gathering the data needed. After this, the researcher will get the academic data needed like GPA in Mathematics 10, GWA in grade 10, NCAE - mathematical ability results and NCAE- STEM results. The researcher used the SPSS for the input and analyzation of the data gathered.

Retention Test Facilitation: The researcher gives the PreCalculus Retention Test (PRT) to the respondents of the study after 4 weeks of taking the post-test in Pre-Calculus. The respondents took the PRT on November 16, 2018. The 2 sections took the PRT simultaneously. The researcher gave the exam to the STEM $11 \mathrm{R}$ while he asked one mathematics senior high school teacher to give the exam to STEM $11 \mathrm{Q}$

Data Analysis: The data were statistically treated to answer the specific questions stated in Chapter 1. Percentage, mean, standard deviation, Pearson Product Moment Coefficient of Correlation and Multiple Regression Analysis were applied. The researcher used IBM Statistical Package for the Social Sciences (SPSS) Statistics version 20 in analyzing the data gathered.

\section{RESULTS AND DISCUSSION}

Out of one hundred three (103) respondents, there are sixty-one (61) or $59.22 \%$ of the respondents are male and forty-two (42) or $40.78 \%$ of the respondents are female. Impliedly, most of the students who are taking Science Technology Engineering and Mathematics (STEM) strand are male. This was supported by the study of Mutai (2020) that boys had a stronger affinity and interest towards mathematics.

The average family monthly income $(\overline{\boldsymbol{x}}=18,932.04, \mathrm{~s}=11,502.141)$ of the respondents of the study indicates that the family of the STEM students earned enough money to sustain their basic needs. However, since there is a huge value in the standard deviation therefore the mean can be affected by the extreme values like those students whose family monthly income are 50,000. In relation with this, it implies that socioeconomic status does not affect the performance of the respondents of the study. This was supported by the mean of GPA in Mathematics 10 and GWA in Grade 10 which states that the respondents of the study have outstanding grades. This indicate that even the students are not well-off in terms of family monthly income, still the students can excel in the class.

The average NCAE - Mathematical Ability results $(\overline{\boldsymbol{x}}=69.15$, $\mathrm{s}=$ 24.537) indicates that the respondents of the study excelled in Mathematics. However, there are still seven (7) or $6.80 \%$ of the respondents who got low results in NCAE-Mathematical Ability. It only indicates that there are still STEM students who need the support and guidance of a Mathematics teacher. Since there is a huge value of standard deviation therefore it implies that the scores of the respondents are widely dispersed. It means that the respondents have different level of mathematical ability using NCAE results. On the study of Ferrer et. al, (2017), it was revealed that NCAE Mathematical Ability of STEM students was 88.4 which implies that most of the students who enrolled in STEM strand is inclined in mathematics. On the other hand, the average NCAE-STEM results $(\overline{\boldsymbol{x}}=75.72, \mathrm{~s}=21.003)$ implies that there should be proper training for the respondents of the study because the mean should be greater than 80 so that to meet the qualification of the Department of Education.

The mean GWA in grade $10(\overline{\boldsymbol{x}}=90.71, \mathrm{~s}=2.750)$ of the respondents indicate an outstanding performance of the respondents when they were in grade 10. It only implies that most of the students who are enrolled in STEM strand are intelligent not only in Mathematics and Science but also in all the learning areas. The average GPA in Mathematics $10(\overline{\boldsymbol{x}}=90.59, \mathrm{~s}=3.136)$ of the respondents indicate an outstanding performance of the respondents in Mathematics. It only implies that most of the students who are enrolled in STEM strand are intelligent and excelled in Mathematics when they were in grade 10. Study of Ferrer et al. (2017) showed the performance of STEM students 
Table 1. Relationship between the PRT Results and the Independent Variables

\begin{tabular}{|c|c|c|c|c|c|c|c|}
\hline & $\begin{array}{c}\text { Computed } \\
\text { r - value }\end{array}$ & $\begin{array}{c}\text { Level of } \\
\text { Significance }\end{array}$ & df & $\begin{array}{c}\text { Critical } \\
\mathbf{r}-\text { value }\end{array}$ & p-value & Decision & Interpretation \\
\hline Gender & -0.095 & 0.05 & 101 & 0.1946 & 0.339 & Accept $\mathrm{H}_{\mathrm{o}}$ & Not Significant \\
\hline Family Monthly Income & 0.015 & 0.05 & 101 & 0.1946 & 0.883 & Accept $\mathrm{H}_{\mathrm{o}}$ & Not Significant \\
\hline NCAE - Math Ability & 0.359 & 0.05 & 101 & 0.1946 & 0.000 & Reject $\mathrm{H}_{\mathrm{o}}$ & Significant \\
\hline NCAE - STEM & 0.249 & 0.05 & 101 & 0.1946 & 0.011 & Reject $\mathrm{H}_{\mathrm{o}}$ & Significant \\
\hline GWA in Grade 10 & 0.465 & 0.05 & 101 & 0.1946 & 0.000 & Reject $\mathrm{H}_{\mathrm{o}}$ & Significant \\
\hline GPA in Math 10 & 0.532 & 0.05 & 101 & 0.1946 & 0.000 & Reject $\mathrm{H}_{\mathrm{o}}$ & Significant \\
\hline
\end{tabular}

Table 2. Mathematical Models in Predicting Retention of STEM Students in Pre-Calculus

\begin{tabular}{|c|c|c|c|c|c|c|}
\hline Model & $\mathbf{R}$ & $\mathbf{R}^{2}$ & Adjusted R ${ }^{2}$ & $\mathbf{F}$ & p-value & Unstandardized Coefficient (B) \\
\hline Constant & & & & & & -31.462 \\
\hline NCAE Math & 0.481 & 0.232 & 0.216 & 14.776 & 0.000 & 0.035 \\
\hline GPA MATH & & & & & & 0.632 \\
\hline Constant & & & & & & -28.370 \\
\hline NCAE Math & 0.433 & 0.187 & 0.171 & 11.287 & 0.000 & 0.033 \\
\hline GWA GRADE10 & & & & & & 0.599 \\
\hline
\end{tabular}

in Mathematics 10 which is 89.6. It indicates that senior high school utilized the DepEd memorandum in accepting STEM students.

In terms of the PRT scores of the respondents of the study, there are only two respondents who got 40 and above scores in PRT. It means that these two students excelled in Pre-Calculus and considered to be an outlier since their score is far from the normal score of the respondents of the study. Thirty-nine (39) or $37.86 \%$ of the respondents got $26-30$ scores in PRT which is considered to be the highest frequency. Furthermore, the average PRT results $\left(x^{-}=28.50, s=5.470\right)$ of the respondents indicate that the respondents still retained the lessons in Pre-Calculus.

As can be gleaned on Table 1, it shows that gender and family monthly income do not have significant relationship between PRT results. However, it contradicts the results of the study of Kashahu (2011) which reveals that the grade of the exam in Mathematics is predicted positively by gender which implies that academic achievement of students of 9th grade is related to sex. In terms of family monthly income, this was supported by the study of Ford (2011) that low income families had significantly lower math scores.

NCAE- Mathematical Ability scores and NCAE- STEM results showed significant relationship between PRT results. It indicates that NCAE-Mathematical ability results can be basis of accepting students who want to enroll in STEM strand. This can be addressed to the Department of Education to revise the qualifications of accepting STEM strand and include the result of NCAE-Mathematical ability in the qualifications. This was supported by the study of Laurista (2012) that the NAT- Mathematics is significantly related to Division Achievement Test - Math and performance in mathematics.

Moreover, GWA in grade 10 and GPA in Mathematics 10 also showed significant relationship between PRT results. This indicate that as the GPA in Mathematics 10 increases, there is moderately increase in Pre-Calculus Retention Test scores of the respondents. It reveals that among the 6 independent variables of the study, GPA in Mathematics 10 has the highest computed r-value. It means that the SHS administrators should look first on the GPA in Mathematics 10 of the students which should be 85 and above as stated in DepEd Order Number 55 series of 2016. It is supported by the study of Ferrer et. al (2017) that there is significant relationship between GPA in Mathematics 10 and NCAE - Mathematical Ability.
It can be seen on the table that the independent variables utilized in the model are NCAE-Math, GPA in Mathematics 10 and GWA in Grade 10 because these are the variables that meet the assumptions for multiple regression analysis which is the computed $r$-value should be greater than 0.3 (see Table 2). However, gender, family monthly income and NCAE-STEM did not meet the assumption because the computed r-value is less than 0.3 (see Table 2). On the other hand, one also of the assumptions of multiple regression analysis is to check the outliers in the PRT results. By the used of the SPSS, it reveals that respondent numbers 6 and 67 are the the outliers that is why the data were omitted. Moreover, since there is a computed r-value of 0.724 between GPA in Mathematics 10 and GWA in grade 10 therefore there is a need for the two independent variables to be separated in making mathematical models to avoid multicollinearity. With this, the study develops two mathematical models that can predict retention of STEM students in Pre-Calculus.

The first model involves the independent variables which are NCAE-Mathematical ability and GPA in Mathematics 10. The multiple regression models with the two predictors produced $\mathrm{R} 2=0.232, \mathrm{~F}(2$, $98)=14.776, p<0.05$. As can be seen on the table that the two predictive variables are positively and significantly correlated with the criterion, indicating that those with higher scores in NCAE - Mathematical ability and higher grades in GPA in Mathematics 10 were expected to have higher scores in Pre-Calculus Retention Test. The statistics indicate that the two independent variables explained $23.2 \%$ of the total variance in PRT scores. A coefficient value of $\beta=0.035$ suggested that for everyone unit increase in NCAE-Mathematical ability, PRT scores increased by 0.035 points. Likewise, a coefficient vale of $\beta=0.632$ suggested that for everyone unit increase in GPA in Mathematics 10, PRT scores increased by 0.632 points. Furthermore, using the standardized coefficients, the formula in predicting retention of STEM students in Pre-Calculus is,

$\mathrm{y}=0.035 \mathrm{x} 1+0.632 \times 2-31.462$

where;

$y$ - PRT scores of the STEM students (dependent variable)

x1 - NCAE-Mathematical Ability scores

x2 - GPA in Mathematics 10 
As can be gleaned on the mathematical model, it shows that the best predictor of the retention of STEM students is the GPA in Mathematics 10 because it contributes the higher value on the PRT scores of the respondents.

The second model involves the independent variables which are NCAE-Mathematical ability and GWA in grade 10. The multiple regression models with the two predictors produced $\mathrm{R} 2=0.187, \mathrm{~F}(2$ $98)=11.287, \mathrm{p}<0.05$. As can be seen on the table that the two predictive variables are positively and significantly correlated with the criterion, indicating that those with higher scores in NCAE - Mathematical ability and higher average in GWA in grade 10 were expected to have higher scores in Pre-Calculus Retention Test. The statistics indicate that the two independent variables explained $18.7 \%$ of the total variance in PRT scores. A coefficient value of $\beta=0.033$ suggested that for everyone unit increase in NCAE-Mathematical ability, PRT scores increased by 0.033 points. Likewise, a coefficient vale of $\beta=0.599$ suggested that for everyone unit increase in GWA in grade 10, PRT scores increased by 0.599 points. Furthermore, using the standardized coefficients, the formula in predicting retention of STEM students in Pre-Calculus is,

$\mathrm{y}=0.033 \mathrm{x} 1+0.599 \mathrm{x} 3-28.370$

where;

$y$ - PRT scores of the STEM students (dependent variable)

x1 - NCAE-Mathematical Ability scores

$\mathrm{x} 3$ - GWA in grade 10

As can be gleaned on the mathematical model, it shows that the best predictor of the retention of STEM students is the GWA in grade 10 because it contributes the higher value on the PRT scores of the respondents.

It can be concluded that the two mathematical models can be utilized by the SHS administrators specifically those schools who are offering STEM strand in accepting students who wanted to enroll in STEM. The researcher innovates an excel file that will enable them to simply encode the GPA in Mathematics 10, GWA in grade 10 and NCAE - Mathematical ability of the students then the retention of the students in Pre-Calculus will be revealed.

\section{RECOMMENDATIONS}

Based on the findings and conclusions, the following recommendations are offered:

1. The SHS administrators should be strict in accepting students who will enroll in STEM, to diminish the number of dropouts and shifting of other strands of the students.

2. Aside from using the qualifications on accepting students as stipulated in the DepEd order number 55 series of 2016, the schools should also utilize the NCAE-Mathematical Ability scores of the students.

3. The innovated excel file aligned with the developed mathematical models can be utilized by the SHS administrators in accepting students who will enroll in STEM strand.

4. The students who wanted to enroll in STEM but fail to meet the qualifications in PRT results should undergo intervention with their Pre-Calculus teachers like remedial teaching.

5. Further studies should be made to include other variables like learning styles, study habits, intelligent quotient and etc.

\section{REFERENCES}

Ahmed Gubbad, A. (2010). The effect of cooperative learning on the academic achievement and retention of the mathematics concepts at the primary school in Holy Makkah. Educational Science and Islamic Studies, 22(2), 13-23.

Akaazua, J. T., Bolaji, D. C., Kajaru, K., Musa, M., \& Bala, K. (2017) Effect of concrete manipulative approach on attitude, retention and performance in Geometry among junior secondary school students in Benue State, Nigeria. IOSR Journal of Research \& Method in Education, 7(6), 80-175. https://doi.org/10.9790/738807060180175

Alkhasawneh, R., \& Hargraves, R. (2014). Developing a Hybrid Model to Predict Student First Year Retention in STEM Disciplines Using Machine Learning Techniques. Journal of STEM Education, 15(3). Retrieved on May 31, 2020 from https://www.learntechlib.org/ $\mathrm{p} / 151110 /$

Chan, J. G. (2019). The labor code of the Philippines, annotated, labor standards and social legislation (Volume 3). ChanRobles Publishing Company.

Ferrer, F. P., \& Dela Cruz, R. J. (2017). Correlation of STEM students' performance in the National Career Assessment Examination and academic subjects. People: International Journal of Social Sciences, 3(1), 532-541. https://doi.org/10.20319/pijss.2017.s31.532541

Ford, F. (2011). The effect of family poverty on children's academic achievement: Parental discussion and neighborhood poverty as mediating variables. Graduate School-Camden Rutgers, The State University of New Jersey. New Jersey, USA.

Furner, J. M. (2017). Helping all Students Become Einstein's using Bibliotherapy when Teaching Mathematics to Prepare Students for a STEM World. Pedagogical Research, 2(1), 01. https://doi.org/10.20897/pedre.201701

Hassan, M. N., Abdullah, A. H., Ismail, N., Suhud, S. N. A., \& Hamzah, M. H. (2019). Mathematics Curriculum Framework for Early Childhood Education Based on Science, Technology, Engineering and Mathematics (STEM). International Electronic Journal of Mathematics Education, 14(1), 15-31. https://doi.org/10.12973/ iejme/3960

Kashahu L. (2011). The impact of gender, some demographic characteristics and parent-teacher relationship on adolescent academic achievement. "Aleksander Moisu” University. Durres, Albania.

Kurumeh, F. S., Onah, F. O., \& Mohammed, A. S. (2012). Improving students' retention in junior secondary school Statistics using the ethno-mathematics teaching approach in Obi and Oju local government areas of Benue State, Nigeria. Greener Journal of Educational Research, 2(3), 54-62. https://doi.org/10.15580/ GJER.2012.3.10051286

Laurista, J. L. (2012). National Career Assessment Examination (NCAE) performance in Mathematics: It's predictors and congruence to students course (Masters Thesis, Arts in Education Major in Secondary Mathematics), West Visayas State University. Iloilo, Philippines.

Mbuva, J. M. 1. (2011). An examination of student retention and student success in high school, college, and university. Journal of Higher Education Theory \& Practice, 11(4), 92-101. 
Modebelu, M., \& Ogbonna C. (2014). Reform-Based-Instructional method and learning styles on students' achievement and retention in Mathematics: Administrative Implications. International Journal of Education and Literacy Studies, 2(2), 48-52. https://doi.org/10.7575/aiac.ijels.v.2n.2p.48

Mutai, C. (2020). Gender differences in Mathematics performance among secondary school students in Bureti Sub - County, Kericho County Kenya (Master of Education Thesis). Kenyatta University. Nairobi, Kenya. http://ir-library.ku.ac.ke/handle/123456789/14968

Nneji, S. (2013). Effect of Polya George's problem-solving model on students' achievement and retention in Algebra. Journal of Educational and Social Research, 3(6), 41-48. https://doi.org/10.5901/jesr.2013.v3n6p41

Ogunkunle, R., \& Henrietta, O. (2014). Effect of differentiated instructional strategies on students' retention in Geometry in FCT senior secondary schools Abuja, Nigeria. Global Journal of Educational Research, 13, 1-7. https://doi.org/10.4314/gjedr.v13i1.1

Radunzel, J., \& Noble, J. (2013). Differential effects on student demographic groups of using $A C T{ }^{\circledR}$ College readiness assessment composite score, $A C T$ benchmarks, and high school grade point average for predicting long-term college success through degree completion (ACT Research Report No. 2012-2). Iowa City, IA: ACT, Inc.

SEI-DOST, \& MATHTED. (2011). Framework for Philippine mathematics teacher education. Manila: SEI-DOST \& MATHTED.
Sharma, H. (2016). Effectiveness of educomp smart classroom teaching on retention in mathematics at elementary level. International Journal of Multidisciplinary Research and Development, 3(6), 160-164.

Siregar, N. C., Rosli, R., Maat, S. M., \& Capraro, M. M. (2020). The Effect of Science, Technology, Engineering and Mathematics (STEM) Program on Students' Achievement in Mathematics: A Meta-Analysis. International Electronic Journal of Mathematics Education, 15(1), em0549. https://doi.org/10.29333/iejme/5885

Staus, N. L., Falk, J. H., Penuel, W., Dierking, L., Wyld, J., \& Bailey, D. (2020). Interested, Disinterested, or Neutral: Exploring STEM Interest Profiles and Pathways in A Low-Income Urban Community. Eurasia Journal of Mathematics, Science and Technology Education, 16(6), em1853. https://doi.org/10.29333/ejmste/7927

Thurston, A., \& Topping, K. (2007). Peer Tutoring in Schools: Cognitive Models and Organizational Typography. Journal of Cognitive Education and Psychology, 6(3), 356-372. https://doi.org/10.1891/194589507787382070

Topping, K., Dehkinet, R., Blanch, S., Corcelles, M., \& Duran, D. (2013). Paradoxical effects of feedback in international online reciprocal peer tutoring. Computers \& Education, 61, 225-231. https://doi.org/10.1016/j.compedu.2012.10.002 